\title{
Turismo e Ensino de História: potencialidades e interpretações locais
}

\author{
Tourism and History Teaching: potencialities and local interpretations
}

Raquel Alvarenga Sena Venera ${ }^{1}$

\begin{abstract}
Resumo
Este artigo é resultado de uma pesquisa sobre as intersecções do Ensino de História na Educação Fundamental desenvolvida nos anos de 2005 a 2008 na Rede Municipal de ensino de Itajaí, Santa Catarina, a partir de narrativas escritas por estudantes das $7^{\mathrm{a}}$ e $8^{\mathrm{a}}$ séries. As análises dessas narrativas foram feitas a partir da Análise do Discurso, AD, com tradição francesa, e evidenciaram tipologias discursivas, entre elas os discursos Histórico e Turístico como marcas nos enunciados dos adolescentes e como essas duas grandes áreas do conhecimento podem potencializar as interpretações locais e incentivar sentimentos como pertencimento, identidade e alteridade - importantes não apenas para os objetivos da História ensinada, mas também para construir desejos e potencialidades de um Turismo mais cultural.
\end{abstract}

Palavras-chave: turismo; ensino de história; patrimônio cultural; memória; narrativas.

\begin{abstract}
This article is a result of a research about the intersections of History Teaching in the Fundamental Education, produced from 2005 to 2008 in the Municipal Education System of Itajai, Santa Catarina, with narratives written by students. The analysis of these narratives were produced based on Discourse Analysis (DA), with French tradition, and evidenced discoursive typologies. Among these typologies, the History and Tourism discourses appear like signs in the adolescents enunciations and how these knowledge areas can potencialize local interpretations and stimulate some feelings, important to the purposes of taught History and to the construction of wishes and potencialities of a cultural Tourism.
\end{abstract}

Keywords: tourism; history teaching; cultural patrimony; memory; narratives.

\footnotetext{
${ }^{1}$ Doutora em Educação pela Unicamp; Mestre em História Cultural pela UFSC; Bacharel e Licenciada em História pela Univali; Professora do curso de História (modalidade presencial) da Univali; Professora do Curso de Mestrado em Turismo e Hotelaria da Univali. Email: raquelsenavenera@hotmail.com.
} 


\section{Introdução}

Este artigo é uma aproximação entre o Ensino de História e o Turismo a partir de narrativas interpretativas sobre a história da cidade de Itajaí, construídas por estudantes das $7^{\mathrm{a}}$ e $8^{\mathrm{a}}$ séries da Educação Fundamental do município. Trata-se de parte dos resultados de uma pesquisa sobre as intersecções do Ensino de História para além da sua ciência de referência - a História. As hipóteses sobre as relações da temática e outras áreas como a Pedagogia, a Psicologia da Aprendizagem, a Política, a Sociologia, a Filosofia e a Antropologia sempre foram óbvias, porém, apesar dos discursos sobre o Turismo não perfazerem as hipóteses iniciais da pesquisa, eles apareceram fortemente marcados nas narrativas desses estudantes.

A pesquisa "Intersecções no Ensino de História" foi iniciada em 2005, em uma parceria entre a Fundação Genésio Miranda Lins - superintendência que administra os museus e acervos históricos da cidade -, o curso de História da Univali e a Secretaria de Educação do município. E em 2008 contou, também, com o apoio do Fundo de Amparo a Pesquisa de Santa Catarina, FAPESC. O objetivo inicial da pesquisa era investigar a construção da proficiência em História dos estudantes da rede municipal e, a partir dos resultados desta investigação, oferecer suporte para a construção de um Livro Didático sobre a história local, e, ao mesmo tempo, disponibilizar subsídios para a formação continuada de professores de História.

A primeira fase da pesquisa considerou 3.889 alunos matriculados nessas séries - sendo 1.802 alunos na $7^{\mathrm{a}}$ série e 2.087 na $8^{\mathrm{a}}$ série -, e optou por uma amostragem de $12 \%$ destes, ou seja, 499 alunos - 235 da $7^{\text {a }}$ série e 264 da $8^{\text {a }}$ série. Esta fase da pesquisa, que aconteceu em 2005 , contou com a participação dos estagiários do curso de História da Univali, matriculados no $5^{\circ}$ período, na disciplina "Prática de Ensino de História" e, foi parte integrante do projeto de estágio da turma em consonância a ementa desta.

Os resultados desta primeira fase da pesquisa orientaram tanto o trabalho de confecção do Livro Didático sobre a história local como as direções da Formação Continuada com os professores de História da Rede Municipal. Neste período, cinco professores, das $7^{\mathrm{a}}$ e $8^{\mathrm{a}}$ séries, se ofereceram, voluntariamente, para utilizar o Livro Didático que estava sendo produzido. Além disso, colocaram suas turmas à disposição para a aplicação da segunda fase da pesquisa. Desta forma, nessa segunda fase o recorte de aplicação foi menor, porque contou 
apenas com uma participação voluntária. Essa segunda fase contava com a hipótese de que o uso de um livro didático sobre as Histórias de Itajaí, relacionadas às outras Histórias, tradicionalmente chamadas de História do Brasil, História da América, História Geral, auxiliaria na construção de uma proficiência em História nos estudantes. E, para isso era necessária a adesão voluntária dos professores. Os resultados da primeira fase da pesquisa apontaram para uma proficiência bastante elementar, principalmente no que diz respeito à localização espacial e temporal de Itajaí em relação a outros locais e tempos, bem como ao repertório histórico das narrativas.

Apesar dos critérios de leitura desta pesquisa ser pautados na disciplina História - e estes critérios fizeram aparecer nas narrativas dos estudantes uma pobreza de conteúdos -, foi observada uma riqueza nos detalhes sobre o Turismo na região.

Diante deste cenário de pesquisa, foi considerado que o fazer docente seria fundamental para o crescimento da proficiência histórica para além do livro didático que estava em construção. E, necessariamente, o professor deveria aderir voluntariamente ao projeto, e não ser convocado a participar. Acreditou-se que este gesto provocaria mudanças nos resultados da pesquisa. A partir desse critério, a segunda fase da pesquisa foi aplicada em 160 alunos, todos da $7^{\text {a }}$ série da Rede Municipal. Nesse novo recorte, o discurso do Turismo foi ainda mais marcante. Os assuntos históricos trabalhados tinham como objetivos a ampliação e o refinamento das narrativas históricas, um acréscimo no repertório sobre as histórias da cidade e, efetivamente, um conhecimento sobre a memória coletiva capaz de sustentar interpretações sobre este lugar. Procurou-se investigar os efeitos de sentidos do consumo cultural dos estudantes na construção dos conceitos de tempo e memória; mapear os efeitos dos elos geracionais dos estudantes nos seus conhecimentos sobre a História.

Os primeiros resultados da primeira fase da pesquisa trouxeram muitas incomodações nas reflexões sobre a ação docente. Todavia, já apresentaram sinais de que os discursos sobre o Turismo na cidade de Itajaí possuem ecos na escola. O primeiro instrumento trazia uma situação hipotética de um acampamento para jovens do mundo todo. Nesse acampamento, ninguém se conhecia e o primeiro desafio era a socialização. Cada um tinha a tarefa de narrar a história do local onde morava e, quanto melhor e mais atrativa ficasse a história, mais chances eles teriam de fazer amigos. Um grande varal seria montado com as histórias 
narradas, todas traduzidas e, a partir do interesse para saber mais sobre esse local, eles seriam procurados em suas barracas e fariam novos amigos.

Propositalmente, não foi explicado o conceito de "local", com o objetivo de mapear o entendimento que os estudantes têm sobre o que seja o local e como se situam no mundo. Apenas $23 \%$ dos estudantes pontuaram a cidade de Itajaí como o local de suas narrativas. A grande maioria - 53,9\% - se localizou na cidade, mas de forma mais restrita ao bairro, recortada a periferia. O sentimento de lugar veio claro onde, efetivamente, a vida deles se passa - nos burburinhos do bairro. Por um lado, os bairros também são a cidade de Itajaí e precisam ser lembrados. Porém, vieram sem o sentido de conjunto, daquilo que faz a cidade ser uma cidade. E, por esse lado, não foram significados como parte de uma memória coletiva. Deste percentual, 35 estudantes destacaram apenas a identificação da rua onde moram.

Como o contexto da pergunta os colocavam frente ao estrangeiro, com a frase "jovens do mundo todo", alguns poucos - 14 estudantes - narraram o Brasil como o seu local de morada, oito fizeram referência ao estado de Santa Catarina e apenas três se situaram como cidadãos do mundo e narraram sobre um local planetário. Nenhum estudante fez referência de pertencimento à América Latina.

Diante disso, o discurso marcado pela História pouco apareceu. Parece que os conceitos, fatos, procedimentos, atitudes planejados e trabalhados nas aulas de História pouco ajudaram para a resolução do problema apresentado no instrumento. Todavia, o Caderno Metodológico de História, disponível aos professores da Rede Municipal de Ensino, sugere que os conteúdos sobre a cidade sejam trabalhados nos anos iniciais do Ensino Fundamental. $\mathrm{Ou}$ seja, esperava-se que os alunos das $7^{\mathrm{a}}$ e $8^{\mathrm{a}}$ séries mostrariam uma proficiência histórica que colocasse Itajaí no tempo presente e passado, no contexto contemporâneo em um processo de rupturas e continuidades.

Apenas 13,5\% das narrativas foram construídas relacionando tempos e espaços diferentes, e $7,2 \%$ delas apresentaram uma Itajaí em processo de mudanças, com sinais de continuidades e rupturas. Cerca de 17\% que apresentaram informações sobre a história da cidade privilegiaram a história do presente, e o que pontuou esta história foi o discurso do Turismo. 
No entanto, quando perguntados três locais onde mais aprenderam sobre a história que narraram, a escola e os elos geracionais - as pessoas mais velhas da família - foram os mais apontados. Como primeira opção apareceu a escola, com 44\% de escolhas, e os elos geracionais, com 29,8\%. No entanto, a terceira opção ficou com a mídia: TV, com 17\% das escolhas, seguida dos jornais, com $16 \%$ delas.

Esses dados nos dizem muito. Quando cruzados, observamos que os cerca de $17 \%$ que apresentaram informações históricas sobre a cidade, os $13 \%$ que conseguiram relacionar tempos e espaços diferentes e, dentre esses, os 7,2\% que apresentaram sinais de rupturas e continuidades na história de Itajaí, reconhecem que aprenderam essas histórias com os elos geracionais, na escola e, poucos ainda, apontaram também o museu e o arquivo histórico da cidade como locais de aprendizagem. Mas, especialmente, estão entre os $69 \%$ que possuem o hábito e gostam de ouvir histórias dos mais velhos da família.

Já na segunda fase da pesquisa, as respostas dos estudantes não mudaram muito a esse respeito. Quando perguntados sobre o local que aprenderam as histórias narradas, mesmo quando o professor havia trabalhado recentemente o assunto, cerca de $40 \%$ indicaram os avós e as pessoas mais velhas da família como fontes de informações sobre a cidade. Os elos geracionais mostraram-se em sua potencialidade como lugar de construção interpretativa sobre a história da cidade.

Esses números nos apontam uma possibilidade de pensar os locais formais do ensino de História, aqueles que possuem padrões para as interpretações sobre as histórias da cidade, mas, sobretudo, e de forma muito especial, aqueles saberes imateriais, como a memória dos mais velhos - patrimônios vivos -, e que, constroem, sobremaneira, bases para interpretar e narrar histórias.

Também permaneceram, na primeira e na segunda fase da pesquisa, as narrativas recortadas mais pelo discurso turístico e pouco ou quase nada pelo discurso da História ensinada. Este viés turístico somou cerca de $15 \%$ das narrativas dos adolescentes. E é este o escopo reflexivo deste artigo.

As tipologias que aqui aparecem chamadas de "discursos Turísticos" e "discursos Históricos" ou "da História Ensinada" foram criados durante as análises das narrativas. Pautada na Analise do Discurso, AD, da corrente francesa, essa pesquisa concordou com Eni Orlandi, 
quando ela diz que "a noção de funcionamento, estendida para o discurso, faz com que não trabalhemos apenas com o que as partes significam, mas que procuremos 'quais são as regras que tornam possivel qualquer parte" (2004, p. 80). Não nos interessou os aspectos formais da língua, que se entendeu estar em processo de construção nesta fase escolar, mas, como os adolescentes fizeram funcionarem sentidos de sedução e de informações históricas em seus textos. Esse trabalho privilegia essa dimensão mais pragmática, que referencia o conhecimento lingüístico junto ao conhecimento das relações sociais, tornando-os híbridos. É a marca histórica da AD. No entanto, a questão aqui apresentada está justamente na fluidez desse lugar praxeológico. Se a dimensão dos usos da língua possui centralidade no interior da $\mathrm{AD}$, e, se esses usos são diversos como são os contextos sociais, se trata de um objeto que é furtivo. E exatamente por essa característica que desliza, ou que escapa os sentidos, ao analista é exigida a construção de um dispositivo teórico de interpretação para cada objeto a ser analisado. A AD inaugura um tipo de análise que precede a teoria. Para cada discurso que será objeto de análise faz-se necessária uma teorização diferenciada. Não existe uma teoria prévia que se encaixa a todos os discursos produzidos em situações históricas diversas.

É nesse sentido que Eni Orlandi, ao introduzir a segunda edição de sua obra A linguagem e seu funcionamento, adverte que "a cada passo, a AD redimensiona seu objeto, reavalia aspectos teóricos e se relaciona criticamente com seu(s) método(s)”. (2003, p.11) A analista do discurso afirma, na obra A inquietação do discurso, organizada por Denise Maldidier, que o exercício de ver a funcionalidade do texto é uma "tarefa ainda mais difícil, quando se trata de uma ciência como a análise de discurso em que a análise precede, em sua constituição, a própria teoria. Ou seja, é porque o analista tem um objeto a ser analisado que a teoria vai-se impondo". (2003, p.10). Desta forma, não existe uma teoria que pudesse contemplar todos os possíveis funcionamentos de um discurso.

É importante, então, definir as características tipológicas dos discursos chamados aqui como turísticos e históricos. Foram dispositivos analíticos de interpretação das narrativas dos adolescentes. A categoria de análise a partir de tipologias discursivas é sugerida pela analista de discursos Eni Orlandi e se funda a partir de características pelas quais se localiza o funcionamento discursivo. São tipos de discurso que revelam as intenções da fala e a forma como este discurso se organiza para cumprir suas intenções. Tanto o tipo histórico quanto o turístico possuem semelhanças, mas, sobretudo, diferem em suas intenções de fala. 
Semelhanças porque ambos se propõem a oferecer uma interpretação sobre o lugar que está sendo apresentado. Possuem uma intenção clara de narrar um lugar ou uma coisa em um tempo. E se diferenciam porque as intenções de sentidos não se encontram, necessariamente.

O discurso recortado pelo Turismo apareceu nas narrativas dos alunos em forma de informações sobre os atrativos da cidade. Algumas narrativas com interpretações mais verticalizadas, outras menos, mas, sobretudo, procuraram apresentar a cidade a partir daquilo que o autor intuiu que poderia seduzir o turista ou o leitor do texto. Fizeram um movimento de fala como se oferecessem algo que consideram um atrativo. Já as narrativas recortadas pela História ensinada ofereceram interpretações que marcam uma ou mais temporalidades, e às vezes repetiram informações convencionadas nas fontes da História no ambiente escolar, como livros didáticos, por exemplo. Ou ainda, operacionalizaram conceitos históricos, como ruptura, continuidade, causalidade, bem como, às vezes, sinalizaram as fontes de informação.

O Ensino de História deposita na construção de narrativas sobre os patrimônios de uma cidade - materiais e imateriais - uma possibilidade de explorar a formação histórica dos sujeitos e atingir consciências históricas. Entende-se por formação histórica - concordando com as historiadoras Sônia Miranda, Sandra Oliveira e Marizete Lucini, no texto "Na esteira da Razão Histórica: olhares e diálogos com a obra de Jorn Rusen”, em livro organizado por Ernesta Zamboni - "como os diferentes processos de aprendizagem em que a História é um assunto privilegiado e não se destina prioritariamente à obtenção de uma competência profissional específica e, sim, à orientação da vida prática, mediante a consciência histórica" (2007, p. 23). Ensinar História nas escolas é, então, constituinte da consciência histórica e esta se opera na linguagem, na possibilidade de interpretar os diversos tempos da ação humana por meio da narrativa. Faço minhas as palavras das autoras ao explicar a consciência histórica e sua relação com as narrativas:

Ela é uma operação intelectual originada das questões do presente em relação ao passado, identificadas e descritas como narrativa histórica. Assim, ao ser mobilizada pela narrativa, a memória torna presente o passado, promovendo uma articulação entre passado rememorado pelas questões do presente em virtude de intenções de agir para o futuro, caracterizando-se pela continuidade. [...] A possibilidade de narrar a experiência temporal, ou seja, a narração dessa consciência histórica, é fator constitutivo da identidade humana, sem a qual não é possível uma orientação para a vida prática, em que os homens agem e sofrem o tempo. (MIRANDA et al., p. 25-26) 
Desta forma, consideramos que a tipologia discursiva histórica se recorta nessa resposta esperada pela História ensinada. Acredita-se que no movimento de construção de narrativas históricas; na visitação de passados em um presente que pergunta; na tentativa de construir interpretações a partir das indagações desse presente, a consciência histórica possa se formar. E, junto dela, uma orientação para a vida prática.

Por outro lado, as narrativas recortadas pelo Turismo não negam as narrativas históricas. Não é uma coisa contrária. No entanto, sua intenção de sentidos passa pela agregação de valores e pelas interpretações que realcem as características de um lugar. Os fins são outros. No entanto, mesmo que não tenha um objetivo pragmaticamente escolar, ainda assim é educacional e também possui intimidade com a formação histórica. Concordando com Freeman Tilden, em apud de Stela Maris Murta e Brian Goodey, a interpretação de um ambiente patrimonial é "uma atividade educacional que objetiva revelar significados $e$ relações através da utilização de objetos originais, de experiências de primeira mão e por meio de mídia ilustrativa, ao invés de simplesmente comunicar informações factuais" (2002, p.14). A partir desta afirmação, dizem que “informar, interpretar é revelar significados, é provocar emoções, é estimular a curiosidade, é entender e inspirar novas atitudes no visitante é proporcionar uma experiência inesquecível com qualidade." (2002, p.14) São essas as características que delineiam a tipologia discursiva turística.

Mas é preciso destacar que os discursos analisados neste artigo foram produzidos em um espaço escolar, durante uma pesquisa com objetivos direcionados ao Ensino de História, como já foi dito. No entanto, muitas das narrativas produzidas mostraram um forte indício de afetos por essa intenção de provocar emoções, curiosidade, inspiração e convite para um visitante. Durante essas análises, algumas perguntas, além daquelas formuladas na pesquisa, foram sendo elaboradas. Como o Ensino de História pode contribuir para a educação turística? Será que a habilidade de ler e interpretar a sua cidade incentiva e desenvolve uma educação para o turismo histórico? Como os discursos turísticos influenciam os discursos que circulam nas salas de aula? Como os discursos turísticos podem colaborar na formação de uma consciência histórica? Foram perguntas levantadas durante as reflexões sobre esta aproximação mapeada na fala dos estudantes. 
A analista de discurso Eni Orlandi, em sua obra "Interpretação", destaca a questão da exterioridade discursiva no gesto da interpretação. Para ela, não existe um dado prévio no texto ou naquilo que o texto diz, mas o que faz uma discursividade é a intervenção entre a produção de uma realidade com a qual o autor está em relação e a memória, o domínio de saber daquele que interpreta. Existe, segundo ela, uma "objetividade contraditória", aquela que, através do sistema lingüístico, fala antes e contraditoriamente a abertura desse sistema no ato de leitura e interpretação.

Segundo a autora, a constituição do discurso se explicita na

[...] memória, o domínio do saber, os outros dizeres já ditos ou possíveis que garantem a formulação (presentificação) do dizer, sua sustentação. Garantia de legibilidade e de interpretação: para que nossas palavras façam um sentido é preciso que (já) signifiquem. Essa impessoalidade de sentido, sua impressão referencial, resulta do efeito de exterioridade: o sentido lá. A objetividade material contraditória. (2004, p.39)

A partir destas reflexões, entende-se que as tipologias discursivas apresentadas oferecem lugares de interpretação para os discursos que vamos analisar neste artigo. São locais onde as falas dos estudantes fazem sentidos, e onde o Turismo e Ensino de História se aproximam de forma materializada.

\section{O Turismo e a História Ensinada nas Narrativas dos Adolescentes}

As falas dos estudantes acionam memórias que significam exteriormente e oferecem perguntas que intrigam e tensionam essas duas áreas discursivas - o Ensino de História e o Turismo. Entende-se também que a criação dessas narrativas contou com textos já ditos (muitas vezes pela mídia) e, nem sempre, foram textos somente produzidos na escola. Como aparece claro no pequeno texto ${ }^{2}$ escrito por Andrielli, 14 anos. É explícita a sua intenção de fala marcada no discurso turístico:

\footnotetext{
${ }^{2}$ Todos os textos dos adolescentes foram digitalizados exatamente como foram escritos. Preservando o dizer e a forma de dizer. Não nos importa aqui se a forma está de acordo com a norma culta da língua, mas, especialmente, os sentidos que elas materializam. Optou-se pela preservação da identidade dos estudantes e todos os nomes citados são fictícios.
} 
[...] moro no estado de Santa Catarina. Um estado belíssimo, realmente maravilhoso. SC possui grandes e incríveis lugares. Qualquer município que você visitar de SC aposto que vai se encantar. SC possui lindas e variadas praias, ladeiras, cachoeiras, arquivos históricos. Cada município possui seu deslumbrante cartão postal. No meu estado foi tudo muito bem projetado. Agora vou falar um pouco do município onde eu moro. A minha linda cidade, nasci aqui quero morrer aqui. Minha cidade destaca-se por ter o segundo maior porto do mundo, destaca-se também por lindas praias, bairros. Possui várias escolas em Itajaí, vários postinhos de saúde. Temos shopping e museu e nosso cartão postal é a Igreja Matriz. Para aprofundar mais o assunto vou comentar sobre o bairro onde eu nasci, cresci e moro até hoje. Meu bairro é calmo, belo e maravilhoso. Tem muita escola, supermercado, lanchonete, tem muitas maravilhas. E assim termina minha história.

A forma de escrever revela pouca habilidade com o texto escrito e pouco repertório que argumente os adjetivos belíssimo, maravilhoso, grandes, incríveis, variadas, deslumbrantes, que aparecem demasiadamente. Todavia, esta forma pouco nos importa do ponto de vista convencional da língua materna, mas expressa a intenção de sedução que marca o discurso turístico. Andrielli interpreta um paraíso turístico. Ela apresenta potencialidades do turismo de verão ao falar das praias; ecológico, ao falar das cachoeiras, ladeiras e praias; histórico, ao falar do arquivo, do museu e de um patrimônio arquitetônico como cartão postal. Ela possui o cuidado de dizer, a sua maneira, que seu estado é organizado, quando utiliza a frase "No meu estado foi tudo muito bem projetado". Imediatamente começa a interpretar Itajaí como possuidora de uma economia sustentável, ao falar do porto. E, em seguida, fala da estrutura social dos bairros, postinhos de saúde, escolas e, também, daquilo que se tem para o turista visitar: shopping, museu. Diante do contexto nacional da violência, Andrielli teve o cuidado de apontar uma diferença do seu bairro: “Meu bairro é calmo (...)”. Tudo isso é interpretado após uma afirmação que soou no texto como um desafio: "aposto que você vai se encantar."

O texto de Andrielli não oferece marcas do discurso histórico. Ela reconhece a importância do arquivo, do museu e dos patrimônios arquitetônicos, porém, os coloca a serviço do turismo. Seu texto é ausente de informações históricas sobre a cidade. Todavia, Andrielli nos dá uma pista de que possui uma subjetivação com este lugar que narra. O pertencimento como um dos objetivos do Ensino da História local parece já estar corporificado na estudante. Ela diz no meio de uma frase, como se não houvesse propósito: "nasci aqui e quero morrer aqui.". 
Paula $^{3}$, sem indicação de idade, utiliza o mesmo movimento do texto de Andrielli. No entanto, recorta sua fala ao bairro onde mora. Ela diz no início do texto: "Não é como na cidade mais é bem legal." Ou seja, ela não promete interpretar um local urbano, "com shopping, museus, porto", mas promete algo interessante. E continua:

O Brilhante é um bairro que pertence a Itajaí, é uma cidade que tem praias e pertence a Santa Catarina que é um estado muito interessante que pertence ao Brasil que é um país com vários apartamentos, shopping e que pertence ao mundo cheio de países.

O Brilhante tem várias cobras, sapos, bicho de vários tipos. Todo ano no dia 8 e 9 de maio o Brilhante organiza uma festa, que é chamada "Festa da Igreja". Também organizam bingos, jantar, para arrecadar dinheiro para a Igreja "Sagrado Coração de Jesus", tem cachorro quente, churrasco, música até de madrugada. A escola também faz festa junina. Fazem até discoteca. Perto de casa tem um pesque pague que todo domingo tem almoço e tem 2 campos de futebol, um de areia e outro de gramado.

O texto de Paula, como o de Andrielli, é desprovido de informações históricas, mas apresenta uma intencionalidade muito forte de interpretar o local onde moram com destaque para aquilo que acham ser "de maior valor". Ambas expressam um sentimento de pertencimento e de identificação com o lugar. Paula situa seu bairro no mundo, informa marcas urbanas quando fala do Brasil - "shopping, apartamento" -, mas ao falar do seu lugar ressalta a diferença "cobras, sapos e bichos de vários tipos". Ela tem a intencionalidade de marcar a diferença. A simplicidade de que fala das festas da igreja e da escola, do pesque pague, interpreta o rústico do lugar. Ela fala sobre esse rústico com uma forma ingênua de escrever. Seu texto parece carregar a mesma simplicidade da qual fala. Ele não possui marcas do discurso histórico, apenas a intencionalidade de sedução, característica marcante do discurso turístico.

Diferente do texto de $\mathrm{J}_{0} \mathrm{a}^{4}{ }^{4}$, sem indicação de idade, que foi atravessado pelo discurso histórico. Porém, pode ser também, tipologicamente, classificado como turístico. Existe uma intenção de interpretar a cidade positivamente, e ele o faz utilizando o discurso histórico. João diz:

\footnotetext{
${ }^{3}$ Paula é um nome fictício. A estudante não se identificou.

${ }^{4}$ João é um nome fictício. O estudante não se identificou.
} 
Eu vou contar sobre a minha cidade, eu não sei muito mas vou contar. Itajaí foi fundada por imigrantes portugueses. O nome Itajaí é homenagem ao rio Itajaí-açu. Em Itajaí a pratica da pesca é normal, junto com os portugueses vieram suas culturas: a pesca, comida, etc...

Todo ano em outubro acontece a marejada. Na marejada tem comida portuguesa, atividade cultural, dança, musica, et. Em Itajaí existi o maior porto do Brasil.

João apresenta uma Itajaí portuguesa. Ele marca um início temporal, um mito de origem tanto nos pioneiros da cidade, quanto na explicação do nome -, mas não se utiliza dos conceitos de rupturas da História. Quando ele junta numa mesma frase o presente e o passado - "Em Itajaí a pratica da pesca é normal, junto com os portugueses vieram suas culturas: a pesca, comida, etc..." -, na verdade oferece ao leitor uma cidade estática no tempo. Em seguida, fala da Marejada como uma culminância dessa inflexibilidade cultural. Todavia, sua intenção é mostrar um cenário para ser apreciado pelo outro. Quase um set como um passado congelado.

Elvira $^{5}$, sem indicação de idade, apresenta uma interpretação semelhante para a História da origem da cidade. No entanto, ela oferece um marco temporal para sua narrativa. Ela diz: “Itajai é colonizada por açorianos e o seu primeiro Sesmeiro foi João Dias Arzão ele veio em 1658. Quando chegaram a história é que encontraram índios canibais". Interessante no texto de Elvira é observar o uso do verbo no presente. Apesar de ela indicar a data de 1658, ela conjuga o verbo no tempo presente, "Itajai é colonizada por açorianos...". João e Elvira interpretam uma história congelada no tempo.

Outros adolescentes conseguiram falar de um lugar que muda no tempo, com rupturas, diferente no tempo da época dos avôs. Um local que recebe pessoas de outros lugares e que, de alguma forma, isso causa mudanças. Um trecho do texto de Pedro ${ }^{6}$, sem indicação de idade, diz um pouco disso, quando ele escreve sobre a Praia Brava: "no começo era tudo muito diferente era poucas casas, o mato predominava mais, e não era muito freqüentado. $A$ Lagoa da Praia era totalmente limpa mas com o tempo e a urbanização, ela foi ficando poluida". Mas Pedro lembra o passado e diz que mora ali "á 12 anos e 4 meses", mas sua família está ali há mais tempo "22 anos". Ele não se sente autorizado a falar sobre a história

\footnotetext{
${ }^{5}$ Elvira é um nome fictício. A estudante não se identificou.

${ }^{6}$ Pedro é um nome fictício. O estudante não se identificou.
} 
de seu bairro: "Eu não conheço nenhuma história antiga, mas pode ser que minha família conheça. [...] eu conheço muitas pessoas já conheci pessoas idosas que sabem tudo da Praia Brava”. Em seu texto, Pedro se dá conta de que as paisagens mudam. Mas ele não consegue ir muito atrás e se justifica na sua pouca idade, mas as pessoas idosas e outras pessoas da família conseguem interpretar historicamente esse lugar.

Pedro nos oferece uma chave de interpretação muito interessante e Gabriela, 14 anos, moradora de um bairro do outro lado da cidade, repete a sugestão. Ela diz: "Este lugar moram muitas pessoas idosas que nos contam como o bairro era há 40, 50 e 60 anos atrás e como o bairro era diferente”. Diferente de João e Elvira, Pedro e Gabriela sabem que as mudanças são muitas e que precisam das memórias para atualizar essas interpretações sobre a cidade. A história de João não precisa das memórias, ela se funda em um mito de origem, e, portanto, trata-se de um ponto inflexível. É uma história cristalizada, oficial, enrijecida e que se repete como um teatro, a cada ano, na Festa Marejada, como ele contou.

Bernardo também se preocupou com a história das origens do seu bairro. Mas foi pontuando rupturas e permanências no decorrer da narrativa. Ele disse:

Eu tenho 14 anos. Eu moro no São Roque. Moro com a minha família tenho um irmão. Meu bairro antes não se chamava assim. Já foi chamado de Toca da Onça. Depois mudou para o conhecido São Roque. Agora mudou para Domingos Rampeloti.

Eu moro no São Roque desde quando nasci. Minha família já morava há 20 anos.

O São Roque antes era rural. Agora com o IPTU não é mais. Mas ainda tem cheiro de estrume e porcos e ainda existem muitas roças.

É um bairro muito legal de morar. É bem calmo aqui é muito bom para andar de skate, pois não passa carro.

É muito bom morar aqui.

O texto de Bernardo pontua as rupturas, quando fala das mudanças no nome do bairro. Ele diz o nome atual - "Agora mudou para Domingos Rampeloti" -, mas, em seguida, refere-se ao nome antigo: "Eu moro no São Roque desde que nasci." Evidenciando que as permanências existem e sobrevivem, em outras palavras ele nos disse que, apesar do nome ter mudado, ele 
mora no São Roque. E continua o texto na mesma direção, dizendo que o bairro era rural e "agora com o IPTU não é mais". Mas, diz ele, "ainda tem cheiro de estrume e porcos e ainda existem muitas roças." Ele não recorre a um passado muito distante, nem às memórias dos mais velhos, fala a partir dos 14 anos em que vive no bairro. Inicia o texto com essa indicação temporal, recorre a ela no meio do texto, dizendo que mora ali desde que nasceu. Ou seja, ele fala do tempo da sua história de vida.

Bernardo mescla as duas tipologias discursivas em seu texto. Ele não apresenta fontes históricas, nem recorre a um passado distante, mas operacionaliza conceitos históricos de forma evidente e, ao mesmo tempo, quer expor aquilo que acha interessante no bairro: "é calmo" e se pode "andar de skate, pois não passa carro".

$\operatorname{Carlos}^{7}$, sem indicação de idade, conseguiu falar sobre uma história originária, mas ofereceu em seguida possibilidades de movimento e mudança. Ele narra:

Lendo o Anuário de Itajaí de 1998, sabemos que em que 1658, o primeiro sesmeiro da região foi João Dias Arzão. Foi em 1777, que a região foi ocupada por agricultores açorianos vindo de Florianópolis e depois de São Francisco do Sul. No século XIX a região foi povoada também por lavradores e pescadores vindos de Paranaguá, São Francisco do Sul, Armação do Itapocorói, Porto Belo e Desterro.

Carlos possui um discurso tipologicamente histórico. Ele pontua o tempo - 1658, 1777, século XIX -, cita a fonte histórica - Anuário de Itajaí -, o tempo em que a fonte foi produzida - 1998 - e indica movimentos na História. Indiferente à assertiva dos dados apresentados, ele oferece uma interpretação do local onde mora a partir da História, sem objetivos de seduzir e incentivar visitantes.

Para terminar essas análises, o texto de Taís ${ }^{8}$, ao contrário de Carlos, oferece apenas apontamentos turísticos. Ela diz: "Itajai é uma cidade com vários pontos turísticos. Gosto muito de Itajaí. Não sei uma história para Itajaí. Itajaí tem belas praias, pontos turísticos: Bico do Papagaio, Museu, morro da Cruz, etc... Praias: Cabeçudas, Praia Brava, Atalaia, etc... Essa é a nossa Itajai”. Taís não possui repertório histórico sobre Itajaí, não apresenta

\footnotetext{
${ }^{7}$ Carlos é um nome fictício. O estudante não se identificou.

${ }^{8}$ Taís é um nome fictício. A estudante não se identificou.
} 
sinais de pertencimento, noções temporais e conceitos da História, apenas apontamentos sobre o mais elementar do discurso turístico: ela lista os pontos de visitação.

\section{Reflexões Finais: o turismo e o ensino de história}

Os dados desta pesquisa suscitaram algumas reflexões acerca da aproximação dessas duas áreas do conhecimento e como elas podem estar em intersecção. Não é novidade que o discurso midiático influencia sobremaneira o público da pesquisa ${ }^{9}$ e que o discurso turístico circula nesse lugar, bem como informações acerca da História. Por outro lado, a pesquisa já se justificava diante da ausência de materiais didáticos e formação de professores sobre a história local e regional. Considerando essas duas questões e a incidência da tipologia do discurso turístico nos textos dos alunos, a hipótese de que o discurso turístico se transforma em material pedagógico em sala de aula, sem a contextualização de sua produção, direcionamento de público e intencionalidade de sentidos, deve ser considerada.

Por outro lado ainda, verificamos que os textos tipologicamente turísticos, quando atravessados verticalmente com os conhecimentos históricos, tornaram-se mais consistentes. As interpretações ficaram mais refinadas. Mesmo que às vezes esses textos trouxeram marcas de uma história mais rígida no tempo, ou quando as informações eram muito recentes, acompanhando o tempo de vida do estudante, mas operacionalizando conceitos históricos, a mescla das duas tipologias trouxe acréscimos aos textos. Os textos que apresentaram apenas as informações históricas se mostraram mais rígidos e menos sedutores. A idéia de interpretar seduzindo o leitor pareceu ter sido um legado do discurso turístico, somado ao pertencimento.

Outra reflexão possível foi a hipótese de que a capacidade de interpretar de forma sedutora e histórica o lugar onde vive sugere a construção de uma sensibilidade de leituras de outros lugares, a que se deu aqui o nome de educação para o turismo histórico. Ou seja, criam-se subjetividades, sensibilidades, interesses para o conhecimento histórico de outros lugares a partir da experiência de contar sobre o seu lugar. Essa é mais uma hipótese que se desdobrou desta pesquisa. Não se trata de construir pequenos guias turísticos, capazes de interpretar seus

\footnotetext{
9 Ver PÁDUA, Alexia; VENERA, Raquel A. S. A memória e o Ensino de História hoje: um desafio nos deslizamentos de sentidos. In: ZAMBONI, Ernesta. (Org.). Digressões sobre o Ensino de História. Itajaí: Maria do Cais, 2007.
} 
locais, mas de turistas em potencial, para o turismo cultural, capazes de desejar conhecer outras histórias, lugares e diferenças. Trata-se, sobretudo, de reconhecer que o Turismo possui responsabilidades com a formação histórica dos sujeitos para além dos turistas reais, mas a área aciona discursos que são consumidas através da mídia e pelas mais diversas formas que são caóticas e incontroláveis e atuam diretamente da construção de identificações dos sujeitos.

Esta pesquisa não se concretizou em um ponto final. Mas aqui ficam as provocações e as possibilidades de continuidade investigativa.

\section{Referências}

MALDIDIER, Denise. 2003. A inquietação do discurso: (re)ler Michel Pêcheux hoje. Tradução Eni Orlandi. Campinas: Pontes.

MURTA, Stela Maris; ALBANO, Celina. (Org.). 2002. Interpretar o Patrimônio: um exercício do olhar. Belo Horizonte: UFMG; Território Brasilis.

ORLANDI, Eni. 2003. A Linguagem e seu Funcionamento: as formas do discurso. $4^{\mathrm{a}}$ ed. Campinas: Pontes.

2004. Interpretação: autoria, leitura e efeitos do trabalho simbólico. Campinas: Pontes.

ZAMBONI, Ernesta. (Org.). 2007. Digressões sobre o ensino de História. Itajaí: Maria do Cais.

Recebido em: 14/02/2010

Aprovado em: 17/07/2010 